\title{
A Survey on Effect of Yoga on Healthy Lifestyle
}

\author{
Deepti Dwivedi and Nimarpreet Kaur \\ Department of Physiology Shree Guru Gobind Singh Tricentary \\ University, Gurugram, Haryana, India \\ Corresponding author email: Deepti_fmhs@sgtuniversity.org
}

\section{ABSTRACT}

In the present scenario, the world is facing crisis in terms of endurance and survival. Everyone in order to fulfill their needs are struggling a lot due to which their mental state has affected a lot. However, struggle is also necessary to fulfil the basic needs of our life. Since these things cannot be controlled but an alternative way can be found regarding the same. Yoga has gained importance from past few years as it provides improved mental state boost immunity. In order to analyze the importance of yoga in one's life a survey is conducted and presented in the present paper. The survey comprises of 250 participants arranged in four different groups ranging from 19-25 years (Group 1), 26-35 years (Group 2), 36-55 years (Group 3) and 56-75 years (Group 4). A questionnaire was provided to them and their responses was collected. The response were then analyzed and results were concluded. It was observed that, the all the groups preferred yoga and practice it in their life. All the participants found yoga advantageous in their life as it helps them to attain inner peace, productive mind, strong immunity and balanced work life as well. Thus it can be concluded that, practicing yoga makes life healthy and cherishable.

\section{KEY WORDS: HEALTH, IMMUNITY, PARTICIPANTS, SURVEY, YOGA.}

\section{INTR ODUCTION}

The world's leading reason of mortality are noncommunicable disorders like cardio-vascular illness, carcinoma, type 2 diabetes and alike(D. K. Taneja et. al. (2014)). Approximately two-thirds of total mortality have occurred. Significant non-communicable diseases risk factors involve modifiable lifestyle, like smoking, unsafe alcohol, poor diets and lack of physical exercise(D. K. Taneja (2014), P. Sengupta (2012)). The World Health Organization (WHO) has established a global aim to minimize the prevalence of non-communicable diseases and resulting premature deaths worldwide by reducing this unhealthy living style(H. Cramer et. al. (2017)). Born in ancient Indian traditions in philosophy, spirituality and wellness, yoga has been popularly recognized to encourage worldwide cognitive and psychosocial well-being. Yoga

Biosc Biotech Res Comm P-ISSN: 0974-6455 E-ISSN: 2321-4007

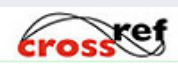

Identifiers and Pagination

Year: 2021 Vol: 14 No (6) Special Issue

Pages: $414-418$

This is an open access article under Creative

Commons License Attribn 4.0 Intl (CC-BY).

DOI: $h t t p: / / d x . d o i . o r g / 10.21786 / b b r c / 14.7 .87$ is also correlated more commonly with physical postures (asane), breathing (pranayama) and meditation (dyana) in Europe, Australia and the United States(D. G. White et. al. (2019)). Yoga is historically a dynamic and balanced lifestyle framework that often includes recommendations. Ethical principles or 'controls' of yoga in particular include recommending action which does not harm one another or anyone. This so-referred 'ahimsa' is addressed as nonviolence towards all living beings - including wildlife, but even towards humans themselves(G. Feuerstein et. al. (2013).

Yoga is effective in both avoidance and anger control disorders. A systemic analysis of eight studies showed that, while promising findings were published, it was not possible to conclude that yoga is effective in treatment of anxiety disorders generally due to methodological deficiencies(M. B. Sullivan et. al. (2018)). However, promising findings, specifically of obsessive compulsive disorder, are presented. A systematic study found positive impacts on depressive disorder from yoga treatments. An analysis of antidepressant victims which were only in partial recovery indicates that depressed, furious, nervous, and neurotic symptoms have been substantially decreased. In comparison to depression research confirms potential of Yoga.

\section{Article Information}

Received: $14^{\text {th }}$ May 2021

ccepted after revision: $28^{\text {th }}$ July 2021 
Figure 1: Representation of Benefits of Yoga. The figure represents some of the major benefits caused due to practicing yoga(M. Sharma et. al. (2020)

\section{Benefits Of Yoga}

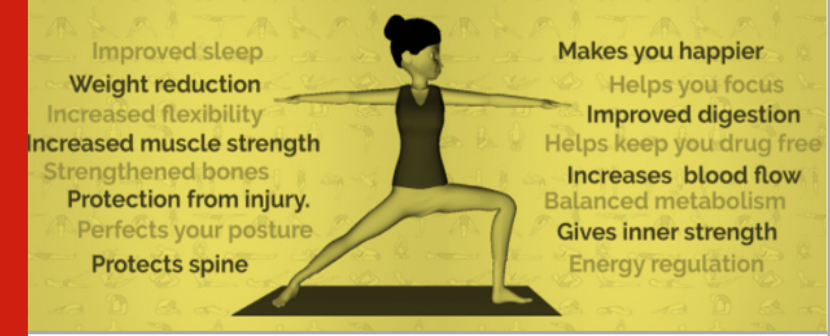

Yoga eliminates fear, depression and grades of salivary cortisol and also levels of plasma rennin and 24-hour urinary Norepinephrine and epinephrine have been shown to be declining. They can be potential mechanisms for yoga influences on stress and illnesses associated with stress, like diabetes, high blood pressure and coronary cardiac disease(Deye et. al. (2013)). Researchers found in 2007 that yoga instructors had higher metabolism and lower painrelated behavior during magnetic resonance imaging (MRIs) scanning among study participants and yoga practitioners. Research illustrates importance of yoga in management of pain reactions and stress(C. Smith et. al. (2007).

Regular yoga exercise creates coolness and intellectual lucidity, increases consciousness of the body, revives tension habits, relaxes mind, and increases concentration. Yoga offers devices in which suffering and sense of helplessness and despair can be dealt(M. Rao et. al. (2017)). Yogic relaxation and stretching practices have resulted in enhanced mental and physical vitality and mood. Yoga also improves cognitive function. Doctors too have indicated that yoga could increase cognitive efficiency.

Though yoga is beneficial to live a healthy life but still due to immense ignorance towards life and involvement in work people do not apply it in life and thus suffers from various diseases. The present research deals with a survey conducted regarding importance of yoga, wherein a group of people were involved and questionnaire was provided to them following which their responses were analyzed and conclusion was drawn. Figure 1 represents benefits of yoga.

Review Of Literature: A survey was conducted on Australian women, wherein women of different age category ranging from 9-67 years regarding smoking, alcohol, or drug abuse, physical behavior, diet, and do they practice yoga or not. Relation between health and yoga was analyzed by using regression analysis. From the results it was analyzed that, 11344,8200 , and 9151 women aged 1925 years, 31-36 years, and 62-67 years, respectively, were involved of which $29.0 \%, 21.7 \%$, and $20.7 \%$, practiced yoga/meditation respectively. It was also observed that, women practicing yoga regularly were more physically active and consume vegetarian or vegan eatables. However, they have also included marijuana and illicit drugs in their $\operatorname{diet}(\mathrm{H}$. Cramer et. al. (2017)). Thus it was concluded that, yoga and meditation activity was linked with vegetarian diet and physical activity. However, practicing marijuana and illicit drugs are not considered good factor for health.

\section{METHODOLOGY}

Design: The survey was conducted by involving participants of different age group. The study involved individuals of different age group. The participants were both male and female. The participants were categorized into different age group and then selected. Four groups were made categorized on the basis of age. The age category was classified as 19-25 years, 26-35 years, 36-55 years, 56-75 years (Table 1). People above 75 were not included as it can be difficult to compare them from aforementioned participant's age. Time taken to complete the survey was one compete day. Necessary arrangements were made for all the participants. Special enclosure and facilities were provided to participants belonging to group 4 .

\begin{tabular}{|c|c|}
\hline Participants & Age category (in years) \\
\hline Group 1 & $19-25$ \\
\hline Group 2 & $26-35$ \\
\hline Group 3 & $36-55$ \\
\hline Group 4 & $56-75$ \\
\hline
\end{tabular}

Table 2. Questionnaire Involved for Conducting Survey

\begin{tabular}{|l|l|}
\hline S.No. & QUESTIONS \\
\hline 1. & $\begin{array}{l}\text { How frequently you have practiced } \\
\text { yoga in last 6 months? }\end{array}$ \\
\hline 2. & $\begin{array}{l}\text { How much rest does the body needs } \\
\text { between yoga sessions? }\end{array}$ \\
\hline 3. & $\begin{array}{l}\text { What is the source of yoga? Do you } \\
\text { prefer online classes or go to yoga centers? }\end{array}$ \\
\hline 4. & $\begin{array}{l}\text { Apart from Yoga are you involved in any } \\
\text { physical activity like walking, heavy } \\
\text { exercises and alike? }\end{array}$ \\
\hline 5. & $\begin{array}{l}\text { What kind of diet you prefer? Veg, } \\
\text { non-veg, vegans? }\end{array}$ \\
\hline 6. & $\begin{array}{l}\text { Do you smoke or consume alcohol?a } \\
\text { Are you involved in any kind of abusive } \\
\text { practices like drugs or faulty medicines? }\end{array}$ \\
\hline 7. & \begin{tabular}{l} 
Why you prefer yoga? \\
\hline 8.
\end{tabular} \\
\hline 9. & $\begin{array}{l}\text { Have you noticed any kind of change in } \\
\text { when you have started practicing yoga? }\end{array}$ \\
\hline
\end{tabular}


Sample: The survey involved planned questionnaire involving selected questions necessary for the survey. The questions were regarding daily life routine, any bad habits like smoking, drinking and alike and how much time they give to yoga. 250 participants were there for the survey classified as 50 members in each group i.e. each group comprising 50 members each.

Instrument: The response from the participants were analyzed thoroughly by conducting a thorough research by a committee of experienced members. While conducting the survey, most important part is the questionnaire with important questions. This is so because selected questions aids in analyzing the perspective of each participants. Four options regarding each question was provided to the participants, comprising, yes, no, never, sometimes. The questionnaire involved herein are as follows: (Table 2).

\section{Data collection}

1. How frequently you have practiced yoga in last 6 months?

\begin{tabular}{|l|c|c|c|c|}
\multirow{2}{*}{ Subjects } & \multicolumn{4}{|l|}{ Response } \\
\cline { 2 - 5 } & Daily & $\begin{array}{c}\text { Thrice } \\
\text { a week }\end{array}$ & $\begin{array}{c}\text { Once } \\
\text { a week }\end{array}$ & $\begin{array}{c}\text { Once a } \\
\text { month }\end{array}$ \\
\hline GROUP 1 & $20 \%$ & $25 \%$ & $40 \%$ & $50 \%$ \\
\hline GROUP 2 & $25 \%$ & $20 \%$ & $35 \%$ & $5 \%$ \\
\hline GROUP 3 & $50 \%$ & $20 \%$ & $15 \%$ & $5 \%$ \\
\hline GROUP 4 & $90 \%$ & $15 \%$ & $10 \%$ & $3 \%$ \\
\hline
\end{tabular}

2.How much rest does the body needs between yoga sessions?

\begin{tabular}{|l|c|c|c|c|}
\hline \multirow{2}{*}{ Subjects } & \multicolumn{3}{|c|}{ Response } \\
\cline { 2 - 5 } & $\mathbf{1 5}$ min & $\mathbf{3 0}$ min & $\mathbf{1}$ hrs & No rest \\
\hline GROUP 1 & $25 \%$ & $20 \%$ & $10 \%$ & $0 \%$ \\
GROUP 2 & $25 \%$ & $27 \%$ & $5 \%$ & $2 \%$ \\
\hline GROUP 3 & $30 \%$ & $20 \%$ & $5 \%$ & $2 \%$ \\
\hline GROUP 4 & $45 \%$ & $30 \%$ & $5 \%$ & $5 \%$ \\
\hline
\end{tabular}

3. What is the source of yoga? Do you prefer online classes or go to yoga centers?

\begin{tabular}{|l|c|c|c|c|}
\hline \multirow{2}{*}{ Subjects } & \multicolumn{3}{|c|}{ Response } \\
\cline { 2 - 5 } & $\begin{array}{c}\text { Online } \\
\text { classes }\end{array}$ & $\begin{array}{c}\text { Yoga } \\
\text { centers }\end{array}$ & $\begin{array}{c}\text { At your } \\
\text { premise }\end{array}$ & Park \\
\hline GROUP 1 & $50 \%$ & $10 \%$ & $20 \%$ & $5 \%$ \\
\hline GROUP 2 & $40 \%$ & $20 \%$ & $50 \%$ & $25 \%$ \\
\hline GROUP 3 & $30 \%$ & $50 \%$ & $35 \%$ & $40 \%$ \\
\hline GROUP 4 & $5 \%$ & $45 \%$ & $10 \%$ & $80 \%$ \\
\hline
\end{tabular}

\begin{tabular}{|c|c|c|c|c|}
\hline \multirow[t]{2}{*}{ Subjects } & \multicolumn{4}{|c|}{ Response } \\
\hline & Yes & No & Never & Sometimes \\
\hline GROUP 1 & $90 \%$ & $5 \%$ & $0 \%$ & $5 \%$ \\
\hline GROUP 2 & $70 \%$ & $10 \%$ & $5 \%$ & $15 \%$ \\
\hline GROUP 3 & $50 \%$ & $30 \%$ & $20 \%$ & $10 \%$ \\
\hline GROUP 4 & $40 \%$ & $50 \%$ & $0 \%$ & $10 \%$ \\
\hline
\end{tabular}

\begin{tabular}{|c|c|c|c|}
\hline \multicolumn{4}{|c|}{$\begin{array}{l}\text { 5.What kind of diet you prefer? } \\
\text { Veg, non-veg, vegans? }\end{array}$} \\
\hline \multirow[t]{2}{*}{ Subjects } & \multicolumn{3}{|l|}{ Response } \\
\hline & Vegetarian & $\begin{array}{c}\text { Non } \\
\text { Vegetarian }\end{array}$ & Vegan \\
\hline GROUP 1 & $60 \%$ & $45 \%$ & $2 \%$ \\
\hline GROUP 2 & $60 \%$ & $40 \%$ & $5 \%$ \\
\hline GROUP 3 & $70 \%$ & $20 \%$ & $5 \%$ \\
\hline GROUP 4 & $95 \%$ & $5 \%$ & $0 \%$ \\
\hline
\end{tabular}

\begin{tabular}{|c|c|c|c|c|}
\hline \multicolumn{5}{|c|}{$\begin{array}{l}\text { 6. Do you smoke or } \\
\text { consume alcohol? }\end{array}$} \\
\hline \multirow{2}{*}{ Subjects } & \multicolumn{4}{|c|}{ Response } \\
\hline & Yes & No & Never & Sometimes \\
\hline GROUP 1 & $85 \%$ & $10 \%$ & $10 \%$ & $25 \%$ \\
\hline GROUP 2 & $70 \%$ & $30 \%$ & $20 \%$ & $10 \%$ \\
\hline GROUP 3 & $20 \%$ & $40 \%$ & $5 \%$ & $30 \%$ \\
\hline GROUP 4 & $5 \%$ & $90 \%$ & $5 \%$ & $5 \%$ \\
\hline
\end{tabular}

7.Are you involved in any kind of abusive practices like drugs or faulty medicines?

\begin{tabular}{|c|c|c|c|c|}
\multirow{2}{*}{ Subjects } & \multicolumn{3}{|c|}{ Response } \\
\cline { 2 - 5 } & Yes & No & Never & Sometimes \\
\hline GROUP 1 & $25 \%$ & $30 \%$ & $10 \%$ & $20 \%$ \\
GROUP 2 & $35 \%$ & $20 \%$ & $15 \%$ & $25 \%$ \\
\hline GROUP 3 & $15 \%$ & $10 \%$ & $50 \%$ & $25 \%$ \\
\hline GROUP 4 & $0 \%$ & $95 \%$ & $95 \%$ & $5 \%$ \\
\hline
\end{tabular}

\section{RESULTS AND DISCUSSION}

1. How frequently you have practiced yoga in last 6 months?: Yoga has become the most crucial activity in one's life when consideration to medical and physical fitness is given. It has gained immense importance in the entire world. It makes the mind calm, relieves stress, makes the body physically fit and keeps the person active throughout the day. Practicing yoga is very important in 
order to enhance the mental state. On asking the review of participants on how frequently they practice yoga their responses were somewhat same and lie within same order. Participants belonging to group 1 preferred yoga only once a month. $50 \%$ of them preferred yoga once a month. Participants belonging to group 2 preferred yoga once a week (25\%), group 3 preferred yoga daily $(50 \%)$ and participants belonging to group 4 preferred yoga daily $(90 \%)$.

\begin{tabular}{l|l|} 
8. Why you prefer yoga? \\
\hline SUBJECTS & RESPONSE \\
\hline GROUP 1 & $\begin{array}{l}\text { Yoga is advantageous as it aids in getting } \\
\text { rid from tension, develops a positive energy, and also } \\
\text { maintains a balance between professional and } \\
\text { personal life. Moreover, it keeps } \\
\text { physically fit and active throughout a day. }\end{array}$ \\
\hline GROUP 2 & $\begin{array}{l}\text { Yoga is beneficial as it provides mental } \\
\text { fitness, boost immunity, and gives inner peace. }\end{array}$ \\
\hline GROUP 3 & $\begin{array}{l}\text { It prevents aging, joint pains and also relieves from } \\
\text { stress caused due to management of personal and professional life. }\end{array}$ \\
\hline GROUP 4 & $\begin{array}{l}\text { It boost immunity, provides inner peace, and are } \\
\text { active to perform their own work. }\end{array}$ \\
\hline
\end{tabular}

9.Have you noticed any kind of change in yourself within past six months i.e. from when you have started practicing yoga?

\begin{tabular}{|c|c|c|c|c|}
\hline \multirow{2}{*}{ Subjects } & \multicolumn{3}{|c|}{ Response } & \multicolumn{2}{|c|}{} \\
\cline { 2 - 5 } & Yes & No & Never & $\begin{array}{c}\text { Partial } \\
\text { Changes }\end{array}$ \\
\hline GROUP 1 & $95 \%$ & $0 \%$ & $0 \%$ & $5 \%$ \\
GROUP 2 & $95 \%$ & $0 \%$ & $0 \%$ & $5 \%$ \\
\hline GROUP 3 & $99 \%$ & $0 \%$ & $0 \%$ & $3 \%$ \\
\hline GROUP 4 & $100 \%$ & $0 \%$ & $0 \%$ & $0 \%$ \\
\hline
\end{tabular}

From the above data it can be concluded that people belonging to group 4 preferred practicing yoga on regular basis followed by participants belonging to group 3, group 2 and group 1. From the data obtained it was inferred that, practicing yoga in one's life is very important in order to achieve the healthy life and improve mental state. Practicing yoga for at least once a day makes one's body so enthusiastic that accomplishing a task becomes possible. Therefore, yoga should become everyone's habit in order to achieve success in life.

2. How much rest does the body needs between yoga sessions?: Having a break from day to day routine is very important without any question. Breaks relaxes the mind and refresh the brain and makes it more productive. While doing continuous exercises muscles stretch a lot, due to which oxygen levels decrease in the muscles and glucose metabolism decreases due to which the person feels so weak and lame. In worst condition sometimes the person even faint. From the survey it was observed that, all the participants preferred rest in yoga sessions. Participants belonging to group 1 preferred a rest for $15 \mathrm{~min}(25 \%)$ while participants belonging to group 2 preferred rest for $30 \mathrm{~min}$. and 3 and 4 preferred rest for $15 \mathrm{~min}$. respectively.
3. What is the source of yoga? Do you prefer online classes or go to yoga centers?: Yoga can be accessed at any place, either online or offline as per the need of the user. If one really wants to practice yoga there is no bar in accessing it. But the thing is that one should be keen learner towards it. When the participants were asked about how they access yoga, all the groups gave a mixed answer depending on their need, time, and money and alike. Participants belonging to group 1 preferred online classes, while those in group 2 preferred practicing yoga at their premise. Participants belonging to group 3 preferred yoga at yoga centers and those in group 4 prefer doing so at park. Different perceptions of different people depends upon their lifestyle, and most importantly time management. People belonging to group 1 and 2 are busy with their career and management of day to day activities due to which they prefer to practice yoga either at their premise or via online classes. However person belonging to group 3 and 4 have some extra time and also they like to enjoy company of each other thus they preferred practicing yoga at centers or at parks.

4. Apart from yoga are you involved in any physical activity like walking, heavy exercises and alike?: Practicing yoga is good, but still involvement in extra activities is also good to live a healthy life. Involvement in different activities entirely depends on the choice of the person. From the survey it was observed that, participants belonging to group 1 also preferred other physical activities in addition to yoga which was $90 \%$ people, while participants belonging to group 2 also preferred physical activities $(70 \%)$ followed by group $3(50 \%)$ and group 4 (40\%).

5. What kind of diet you prefer? Veg, non-veg, vegans?: For attaining a proper health a balanced diet, more preferably yogic diet is very important. It gives immense power and keeps the body active. Yogic diet certainly provides a positive attitude to one's mind which is sufficient 
enough to maintain a proper health. Form the survey it was observed that, all the participants were vegetarians ranging from group 1 to group 4 (60\%-95\%) who practice yoga on a regular basis. However, $45 \%$ of participants from group 1 also preferred non-vegetarian food. This may be attributable to the fact that, youngsters (19-25 years) possess good digestion capacity in comparison to other age groups thus they can manage the yogic diet accordingly.

6. Do you smoke or consume alcohol?: Smoking and alcohol affects the health adversely. The nicotine and carbon monoxide within smoke affects block the arteries by making the blood thick thus affects the oxygen level within the body and blood flow stops(IRCT20160731029134N2 et. al. (2019)). This consequently affects the exercise practice, stretching of muscles, and thus renders the person inactive. From the survey it was observed that, $85 \%$ of participants in group 1 more likely preferred smoking followed by group 2 $(70 \%)$, group $3(20 \%)$ and very few participants in group 4 preferred smoking and alcohol consumption. From the data above it can be inferred that, consumption of alcohol and smoke affects the health badly due to which participants feel lazy and avoid yoga practice.

7. Are you involved in any kind of abusive practices like drugs or illegitimate medicines?: Abusive drugs comprising weeds from cannabis family directly affects the mind and body of the person. Delta-9-tetrahydrocannabinol in the weed alters the mind adversely that renders the mind unconscious for many hours by adversely affecting the sensory motors of the brain(S. Harper et. al. (2012)). Thus it is unethical and illegal to consume abusive drugs. However, still most of the people consume it by arranging them in illegal way. Effect of such abusive drugs adversely affects the life of the person. From the survey it was observed that, participants practicing yoga are not involved in such activities. However, few of them are involved in doing so.

8. Why you prefer yoga?: Answer to these questions varied among different groups according to their perception. One thing common among them was that all preferred yoga because of mental peace and stong immunity they get.

\section{Have you noticed any kind of change in yourself within past six months i.e. from when you have started practicing yoga?: After conducting the survey a last question was asked from the participant's whether they saw any change within themselves after practicing yoga or not. The response from all the participants was positive. 95\% of participants from group 1 and 2 saw the changes within themselves, $99 \%$ of participants belonging from group 3 saw the changes within themselves and $100 \%$ of participants from group 4 saw a change within themselves. This infers that all the participants were benefited from yoga.}

\section{CONCLUSION}

Importance of yoga is multi-dimensional and also its scope has evolved in present era. Thus it can be concluded that yoga is a boon in this modern technological world. Even yoga survey has received international recognition as well. The aim to conduct the survey was to know the importance of yoga in one's life. Form the survey conducted comprising different groups it was observed that each and every group practice yoga in their routine. However, their time management and priority differs but still it is a part of their life. The survey also showed that participants were in addition to practicing yoga also have healthy diet, take proper rest, prefer both online and offline sources of yoga according to their needs, refrains from consuming smoke or alcohol and abusive drugs.

This clearly indicates that they are serious about their life and are honest towards practicing yoga. Moreover, they have seen immense improvement in themselves after practicing yoga for 6 months. Each group have different perception towards yoga when they were asked about importance of yoga in their life. But the conclusion from their perceptions was same that they practice yoga in order to have inner peace, enhanced mental state and strong immunity.

\section{REFERENCES}

Deye, F., Vincent Michel, P. and Ehrmann, S., 2013. Changes in cardiac arrest patientsâ€ TM temperature management after the 2013 â€ œTTMâ€• trial: Results from an international survey. Annals of Intensive, 6(1), pp.737-750.

Feuerstein, G., 2013. The Yoga Tradition: It's History, Literature, Philosophy and Practice. 3rd Prescott, Arizona: Ed.

Harper, S., Strumpf, E.C. and Kaufman, J.S., 2012. Do medical marijuana laws increase marijuana use? Replication study and extension. Annals of epidemiology, 22(3), pp.207-212.

Rao, M., Metri, K.G., Raghuram, N. and Hongasandra, N.R., 2017. Effects of Mind Sound Resonance Technique (Yogic Relaxation) on Psychological States, Sleep Quality, and Cognitive Functions in Female Teachers: A Randomized, Controlled Trial. Advances in mind-body medicine, 31(1), pp.4-9.

Sengupta, P., 2012. Health impacts of yoga and pranayama: A state-of-the-art review. International journal of preventive medicine, 3(7), p.444.

Smith, C., Hancock, H., Blake-Mortimer, J. and Eckert, K., 2007. A randomised comparative trial of yoga and relaxation to reduce stress and anxiety. Complementary therapies in medicine, 15(2), pp.77-83.

Sullivan, M.B., Erb, M., Schmalzl, L., Moonaz, S., Noggle Taylor, J. and Porges, S.W., 2018. Yoga therapy and polyvagal theory: The convergence of traditional wisdom and contemporary neuroscience for self-regulation and resilience. Frontiers in human neuroscience, 12, p.67.

Taneja, D.K., 2014. Yoga and health. Indian journal of community medicine: official publication of Indian Association of Preventive \& Social Medicine, 39(2), p.68.

Vickers, N.J., 2017. Animal communication: when i'm calling you, will you answer too?. Current biology, 27(14), pp.R713-R715.

White, D.G., 2011. Yoga, brief history of an idea. In Yoga in practice (pp. 1-23). Princeton University Press. 